DOI: $10.5216 /$ cab.v14i3.16447

\title{
CARACTERÍSTICAS MORFOLÓGICAS DO FUNÍCULO ESPERMÁTICO DE CAPRINOS COM ESCROTO BIPARTIDO E NÃO BIPARTIDO
}

\author{
Aline SoARES Nunes ${ }^{1}$, AÍrTON MENDES CONDE JÚNIOR ${ }^{2}$, MAÍRA SOARES FERRAZ ${ }^{3}$, ANTÔNIO \\ Augusto NASCIMENTO MACHADO JÚNIOR ${ }^{3}$, DEISE CRISTINE SCHRODER ${ }^{4}$, MARIA ACELINA MARTINS \\ CARVALHO $^{2}$ \\ ${ }^{1}$ Mestre em Ciência Animal, Universidade Federal do Piauí, Teresina, PI, Brasil \\ ${ }^{2}$ Professores Doutores, Universidade Federal do Piauí, Teresina, PI, Brasil \\ ${ }^{3}$ Professoers Doutores, Universidade Federal do Piauí, Bom Jesus, PI, Brasil - mairasferraz@ yahoo.com.br \\ ${ }^{4}$ Médica Veterinária, Joinville, SC, Brasil.
}

Estudou-se a morfologia do funículo espermático em caprinos com escroto bipartido e não bipartido. Foram formados três grupos de caprinos: I - escroto não bipartido; II - escroto bipartido até $50 \%$ do comprimento testicular; e III - escroto bipartido acima de 50\% do comprimento testicular. O comprimento do funículo espermático, o músculo cremáster, o segmento da artéria testicular do funículo e histologia do funículo espermático foram avaliados. Em todos os grupos, a artéria testicular mostrou-se única $(95 \%)$ ou dividida $(5 \%)$, rodeada por veias sem válvulas e com diâmetros variados e irregulares. No grupo I, o tecido adiposo subcapsular envolvia as veias, fato não observado nos demais grupos. Nos grupos
II e III, esse tecido apresentou-se em placas, circundando o funículo, tornando-se mais espesso próximo ao mesoducto, sugerindo isolamento térmico entre os vasos e o ducto deferente. Os caprinos do grupo III apresentaram maior comprimento do funículo (média $=10,25 \mathrm{~cm}$ ) e da artéria testicular (média $=152,80 \mathrm{~cm}$ ), em comparação com os grupos I (8,06 e 103,25 cm) e II $(8,60$ e $121,80 \mathrm{~cm})$. Esse fato pode favorecer as trocas térmicas entre sangue arterial e venoso. O comprimento do músculo cremáster não diferiu estatisticamente $(\mathrm{P}>0,05)$ entre os grupos I $(19,37 \mathrm{~cm})$, II $(18,61 \mathrm{~cm})$ e III $(20,06 \mathrm{~cm})$. Desse modo, concluiu-se que a bipartição escrotal proporciona variações no funículo espermático de caprinos.

PALAVRAS-CHAVE: artéria testicular; músculo cremáster; termorregulação; veia testicular.

\section{MORPHOLOGICAL CHARACTERISTICS OF THE SPERMATIC FUNICLE BETWEEN GOATS WITH OR WITHOUGHT SCROTAL BIPARTITION}

\section{ABSTRACT}

We studied the morphology of the spermatic funicle in goats according to their scrotum conformation. Animals were divided into three experimental groups: I - nonbipartite scrotum; II - bipartite scrotum up to $50 \%$ of testicular length; and III - bipartite scrotum over $50 \%$ of testicular length. We evaluated the length of the spermatic funicle, cremaster muscle, the segment of the umbilical artery and spermatic funicle histology. In all groups the testicular artery was found to be single $(95 \%)$ or divided $(5 \%)$, surrounded by numerous veins without valves and varied and irregular diameters. In group I, the subcapsular adipose tissue was involving the veins. In groups II and III, this tissue was showed as plates surrounding the funicle, becoming thicker near the mesoductus, suggesting the presence of thermal insulation between the vessels and the vas deferens. We found that goats from group III showed greater length of funiculus (mean $=10.25 \mathrm{~cm}$ ) and testicular artery $($ mean $=152.80 \mathrm{~cm})$, in comparison with groups I (8.06 and $103.25 \mathrm{~cm})$ and II $(8.60$ and 121.80 $\mathrm{cm})$. This may facilitate heat exchange between arterial 
and venous blood. The length of the cremaster muscle did not differ statistically $(\mathrm{P}>0.05)$ between groups I (19.37

$\mathrm{cm})$, II (18.61) and III (20.06 cm).

KEYWORDS: cremaster muscle; testicular artery; testicular vein; thermoregulation.

\section{INTRODUÇÃO}

A reprodução animal pode ser entendida como a interação entre o genótipo do animal e a influência dos fatores ambientais (SANTOS et al., 1998). Como parte do processo evolutivo, o surgimento de adaptações morfológicas em resposta às variações das condições ambientais onde o animal vive colabora para a sobrevivência da espécie. A bipartição do escroto foi observada por NUNES et al. (1983) em caprinos na Região Nordeste do Brasil. Para PASCUALY \& ELOY (1985), essa característica aumenta de forma considerável a superfície de cada testículo exposta à temperatura ambiente.

A bipartição escrotal contribui para uma maior aeração e dissipação de calor, equilibrando a produção espermática (MACHADO JÚNIOR et al., 2009), conferindo sêmem de qualidade superior aos caprinos com escroto bipartido criados em regiões de elevadas temperaturas ambientais (CEZAR et al., 2002; ALMEIDA et al., 2008a). A qualidade espermática desses animais pode ser explicada pela melhoria da termorregulação testicular que, segundo SETCHELL \& BREED (2006), deve-se à distribuição e organização anatômica das artérias e veias do funículo espermático, capazes de proporcionar um eficiente mecanismo de contracorrente, reduzindo, assim, a temperatura do sangue arterial.

O presente trabalho teve por objetivo estudar as características morfológicas do funículo espermático em caprinos com escroto bipartido, confrontando-as com as evidenciadas em caprinos com escroto não bipartido.

\section{MATERIAL E MÉTODOS}

Foram utilizados conjuntos de funículo espermático e testículos de 51 caprinos adultos, sem raça definida, nativos do Estado do Piauí, os quais foram coletados em abatedouros do município de Teresina, Piauí.

Observou-se o grau de bipartição do escroto dos animais, separando-os em três grupos de acordo com a configuração escrotal: grupo I caprinos com escroto não bipartido; grupo II - caprinos com escroto bipartido até $50 \%$ do comprimento testicular; e grupo III - caprinos com escroto bipartido superior a $50 \%$ do comprimento testicular.

Foram obtidas medidas do comprimento do músculo cremáster e do funículo espermático, bem como do diâmetro do funículo nas regiões proximal, média e distal em 21 caprinos, sendo sete de cada grupo, utilizando-se um paquímetro (Vernier Caliper, para quatro mensurações, $150 \mathrm{~mm} \times 0,02 \mathrm{~mm}$ ).

Desses animais, cinco de cada grupo foram utilizados para avaliação histológica dos funículos espermáticos. Para tanto, as artérias testiculares foram canuladas e solução salina à $0,9 \%$ foi injetada sob pressão, de modo a efetuar uma lavagem no sistema vascular testicular, sendo posteriormente injetada solução tamponada de formaldeído à $10 \%(\mathrm{pH}$ em torno de 7,0$)$ para a fixação das peças. Fragmentos transversais das regiões proximal, média e distal dos funículos espermáticos foram retirados e submersos em formaldeído tamponado à $10 \%$ com pH em torno de 7,0. O material coletado permaneceu por 48 horas no fixador, sendo então submetido à rotina histológica convencional, com inclusão em parafina. Realizaram-se cortes de 5,0 $\mu \mathrm{m}$ de espessura, os quais foram corados pelos métodos de hematoxilina/eosina e Picrusirius Red, para observação das fibras colágenas em microscópio de luz polarizada e, ainda, pelo método de Weigert para observação das fibras elásticas. A análise do material foi realizada em microscópio de luz e as imagens obtidas foram documentadas em sistema fotomicrográfico (Olympus, modelo BX41) com ocular 10x acopladas a objetivas de 5 e $10 x$.

Para mensuração do comprimento da artéria testicular no funículo espermático, desde o anel inguinal até o testículo, foram utilizados 30 caprinos, sendo 10 de cada grupo. As artérias foram dissecadas, canuladas e lavadas com solução fisiológica $0,9 \%$. Em seguida, injetou-se látex (bi-centrifugado-Cis-I-4) corado, até que o mesmo alcançasse o interior do testículo. Os testículos foram, então, submetidos à corrosão em ácido sulfúrico à $30 \%$, durante um período médio de três dias. Após esse processo, os vasos foram 
encaixados em sulcos de aproximadamente dois centímetros de espessura, feitos num suporte de madeira de 50 centímetros de comprimento, para mensuração com auxílio de régua milimetrada.

A análise estatística deste estudo baseou-se em análise de variância para um delineamento inteiramente ao acaso em esquema fatorial $3 \times 2$, constituído por três grupos (grupo I, grupo II e grupo III) e dois antímeros (direito e esquerdo), com sete repetições para os dados referentes ao funículo e músculo cremáster e dez repetições para comprimento da artéria testicular. As médias foram comparadas pelo teste Student-NewmanKeuls (SNK) a $5 \%$ de probabilidade de erro.

\section{RESULTADOS E DISCUSSÃO}

Na Figura 1 pode-se observar a diferença na morfologia escrotal dos caprinos. Nesses animais, independente do grupo pesquisado, a artéria testicular, dentro do funículo espermático, apresentou inicialmente trajeto retilíneo, tornandose, posteriormente, espiralada e as veias, que formam o plexo pampiniforme, encontravam-se disposta envolvendo a artéria. As espirais aumentam de número da região proximal à distal, semelhante ao observado em ovinos da raça Corriedale (CARVALHAL et al., 2000). Segundo POLGUJ et al. (2011), a artéria testicular de bovinos é formada por numerosos giros irregulares, que constituem uma estrutura cônica com base instalada na porção proximal da gônada. Segundo esses autores, entre a artéria testicular e as veias do plexo pampiniforme, ocorrem conexões indiretas, as quais são formadas pela rede vasa vasorum das artérias testiculares. Os autores afirmam ainda que a distância entre a artéria e as veias difere entre raças e espécies. Segundo BRITO et al. (2004), essa distância é menor em touros zebuínos que em touros mestiços e taurinos e que, quanto menor é a distância entre estes vasos, maior é a troca de calor entre sangue arterial e venoso. Fato que pode explicar a maior resistência de touros Bos indicus bulls às elevadas temperaturas ambientais.

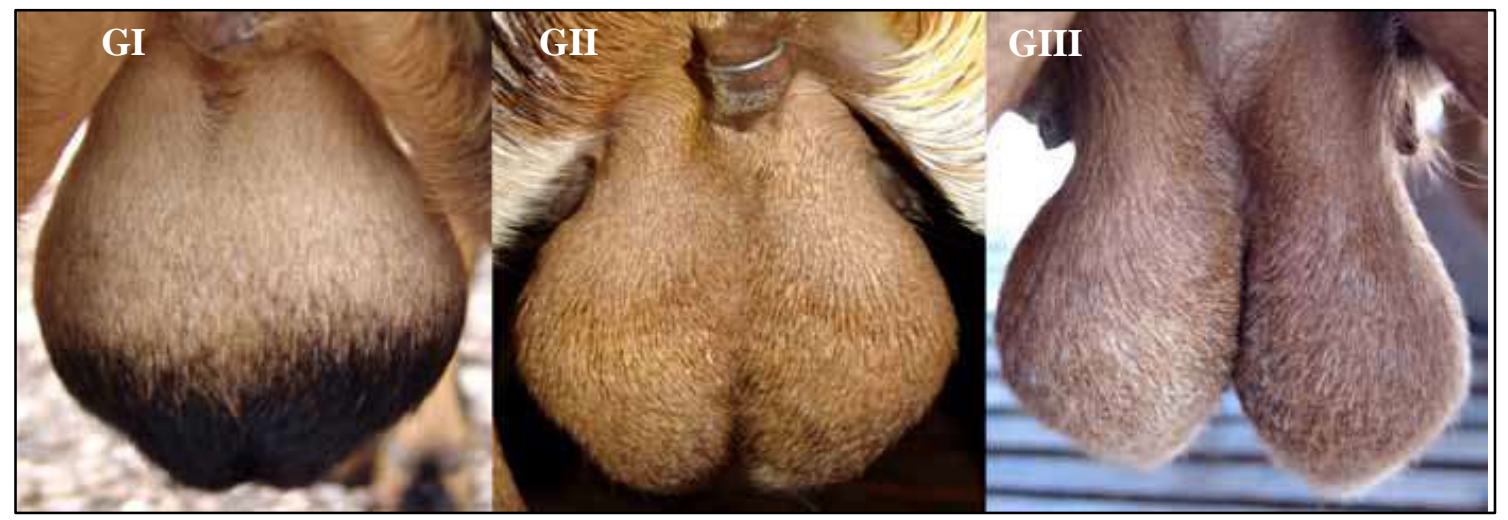

Figura 1. Fotografia evidenciando a região escrotal dos caprinos dos três grupos estudados. GI caprinos do grupo I; GII - animais do grupo II; GIII - caprinos do grupo III (MACHADO JÚNIOR et al., 2009).

Na região medial do funículo dos caprinos avaliados, observou-se o mesoducto deferente com o ducto deferente, suas artérias e veias, conforme observações de SETCHELL \& BREED (2006).

O funículo espermático dos três grupos apresentou-se envolvido externamente pela túnica vaginal formada de tecido conjuntivo denso fribroelástico, constituído de fibras colágenas tipo I e fibras elásticas e de dois folhetos - o parietal, mais espesso, e o visceral, que se molda intimamente ao funículo espermático - os quais encontram-se ligados na face caudal por uma faixa de tecido conjuntivo denso fibroelástico denominado mesofunículo (Figura 2). Essa conformação corrobora com dados obtidos em ovinos da raça Corriedale (CARVALHAL et al., 2000). O folheto visceral, da túnica vaginal, apresenta-se revestido por tecido mesotelial, estando intimamente ligado ao funículo espermático. Essa estrutura forma a cápsula funicular que circunda, de forma irregular, o conjunto vásculo-nervoso. Em alguns pontos, apresenta-se pregueada, projetando-se para formar o mesoducto deferente na região medial do funículo. 


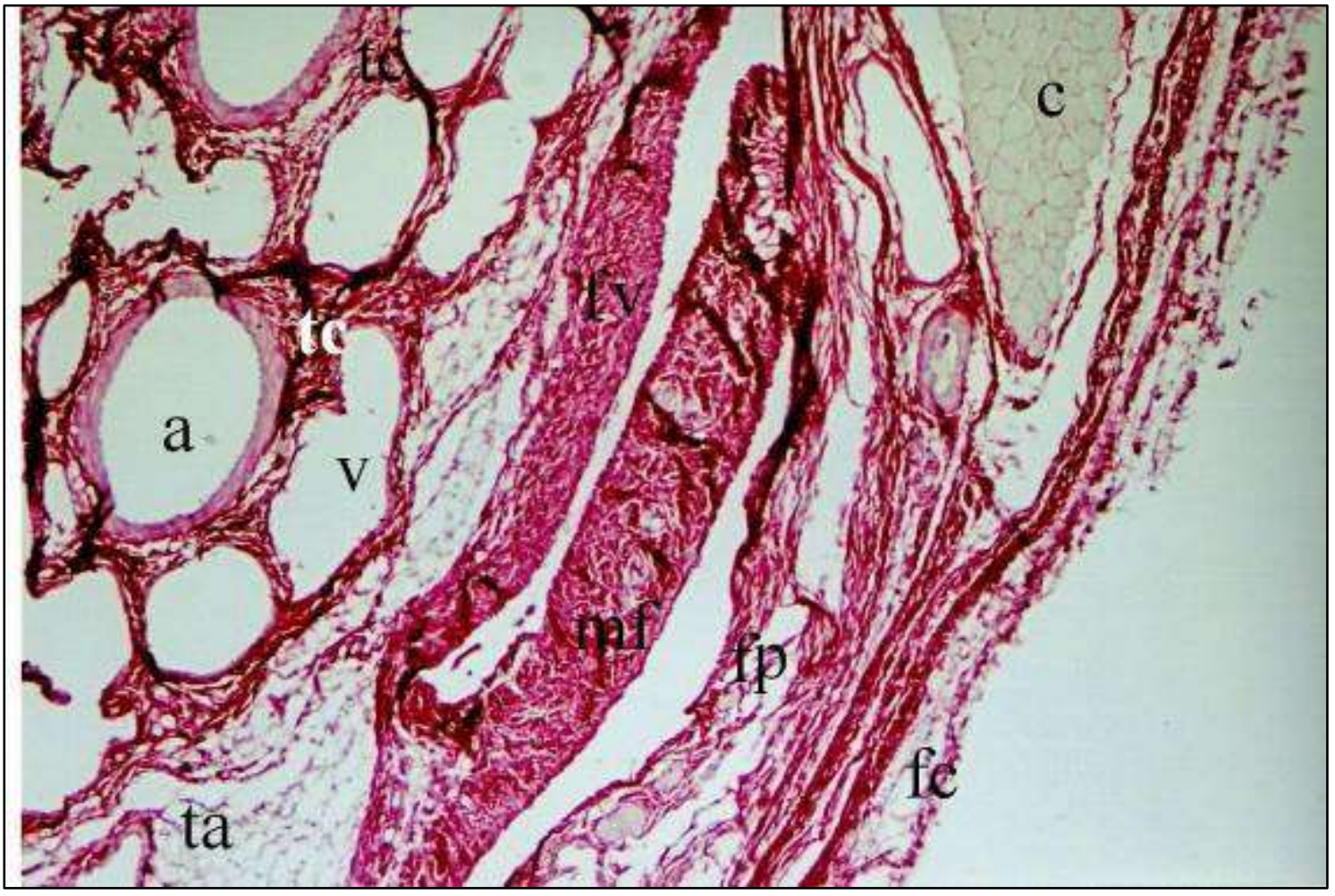

Figura 2. Fotomicrografia da região distal do funículo espermático de caprino pertencente ao grupo II. Notam-se o mesofunículo (mf); os folhetos visceral (fv) e a parietal (fp) da túnica vaginal; tecido adiposo subcapsular (ta), tecido conjuntivo denso intervascular (tc), músculo cremáster (c) e fáscia cremastérica (fc). Método Picrossirius Red. Aumento de 530x

Na porção subcapsular, em todos os grupos pesquisados, encontrou-se uma camada regular de tecido conjuntivo frouxo de espessura variável envolvendo o funículo espermático. Esse tecido conjuntivo, subcapsular e intervascular foi também identificado em outros ruminantes (CARVALHAL et al., 2000; BRITO et al., 2004) e sua função é atuar como tecido de sustentação para as estruturas que compõem o funículo espermático. Acredita-se que a presença desse tecido não tenha muita influência na perda de calor da artéria para a veia testicular, pois, segundo MACHADO JÚNIOR et al. (2009), existe diferença entre a temperatura escroto-testicular de caprinos com e sem bipartição escrotal, mesmo que ambos os grupos possuam tecido conjuntivo envolvendo o funículo.

$\mathrm{O}$ tecido conjuntivo frouxo do funículo espermático vem acompanhado de tecido adiposo, o qual foi encontrado em maior quantidade na porção distal, diferenciando-se de acordo com a configuração escrotal. No grupo I, o tecido adiposo estava escassamente distribuído de forma irregular em placas, na região subcapsular, de forma semelhante ao observado por CARVALHAL et al. (2000) em ovinos da raça Corriedale. Nesse caso, segundo os autores, o tecido adiposo não realiza função isolante térmica por não formar um envoltório do funículo espermático. No grupo II, as placas de tecido adiposo mostraram-se mais extensas e espessas semelhante ao observado no grupo I, concentrando-se próximas ao mesoducto na região subcapsular. No grupo III, no entanto, verificou-se uma grande quantidade de tecido adiposo disposto de forma regular, formando uma camada sob o tecido conjuntivo frouxo subcapsular, conforme descrito por VIANA \& BORELLI (1991) em bovinos. Nesses animais, segundo esses autores, o tecido adiposo forma um verdadeiro envoltório em torno do funículo espermático e possui função de isolante térmico. Acredita-se que nos caprinos essa função isolante também ocorra, pois MACHADO JÚNIOR et al. (2009) observaram que, no período do ano de temperaturas mais elevadas, os caprinos com escroto bipartido matinham a temperatura escroto-testicular menor que os caprinos sem bipartição, provavelmente em função do tecido adiposo impedir a entrada da temperatura ambiente para o funículo espermático.

Entre os vasos do funículo espermático de todos os grupos pesquisados, verificou-se a presença 
de tecido conjuntivo intervascular rico em fibras colágenas tipo I, entremeado por fibras elásticas. Esae tecido encontra-se intimamente ligado à adventícia das artérias e das veias. Essa característica está presente também em ovinos (CARVALHAL et al., 2000).

Algumas artérias apresentaram-se com lúmen de dimensão variada. Essas artérias constituíam-se de adventícia, camada média, formada por fibras musculares lisas, e camada interna (endotélio) com concentração de fibras elásticas. As veias, desprovidas de válvulas e em posição subcapsular, encontravam-se rodeadas por tecido adiposo, grupo I, ou tecido conjuntivo frouxo, grupo II e III, enquanto as veias que se localizavam próximas da artéria testicular apresentaram contornos irregulares, túnica média delgada e adventícia fibro-elástica, corroborando os relatos de SETCHELL \& BREED (2006).
Os resultados morfométricos do funículo espermático e seus componentes encontram-se expressos nas Tabelas 1, 2 e 3. O diâmetro do funículo em caprinos com escroto bipartido, grupo II e III, apresentou médias superiores ao observado para o grupo I, nas porções média e distal (Tabela 1). O comprimento do funículo no grupo III $(10,25 \mathrm{~cm})$ apresentou-se estatisticamente superior $(\mathrm{P}<0,05)$ aos grupos I e II $(8,06 \mathrm{~cm}$ e $8,60 \mathrm{~cm}$, respectivamente), os quais não diferiram estatisticamente entre si. $\mathrm{O}$ comprimento do músculo cremáster não apresentou diferença estatística $(\mathrm{P}>0,05)$ entre as médias dos grupos estudados (grupo $\mathrm{I}=19,66 \mathrm{~cm}$, grupo $\mathrm{II}=$ $18,58 \mathrm{~cm}$ e grupo III $=20,28 \mathrm{~cm})($ Tabela 2$)$. No entanto, como não foram encontrados relatos na literatura sobre esses parâmetros morfométricos para animais contendo a bipartição escrotal, não foi possível estabelecer uma comparação com os resultados obtidos no presente estudo.

Tabela 1. Médias do diâmetro $(\mathrm{cm})$ nas regiões proximal, média e distal e do comprimento $(\mathrm{cm})$ do funículo espermático direito e esquerdo em caprinos com diferentes configurações escrotais: grupo I, escroto único; grupo II, bipartição escrotal até 50\% do comprimento testicular; e grupo III, bipartição superior a 50\% do comprimento testicular

\begin{tabular}{|c|c|c|c|c|c|c|}
\hline \multirow{2}{*}{ GRUPO } & \multicolumn{3}{|c|}{ DIÂMETRO $(\mathrm{cm})^{1}$} & \multicolumn{3}{|c|}{ COMPRIMENTO $(\mathrm{cm})$} \\
\hline & Proximal & Média & Distal & Direito & Esquerdo & Média \\
\hline I & $0,86^{\mathrm{b}}$ & $1,06^{b}$ & $1,76^{\mathrm{b}}$ & $8,28^{\mathrm{b}}$ & $7,84^{b}$ & $8,06^{b}$ \\
\hline II & $1.18^{\mathrm{a}}$ & $1.24^{\mathrm{ab}}$ & $1.96^{\mathrm{a}}$ & $8,37^{\mathrm{b}}$ & $8,82^{\mathrm{b}}$ & $8.60^{\mathrm{b}}$ \\
\hline III & $0,91^{\mathrm{b}}$ & $1,36^{\mathrm{a}}$ & $1,91^{\mathrm{a}}$ & $10,46^{\mathrm{a}}$ & $10,04^{\mathrm{a}}$ & $10,25^{\mathrm{a}}$ \\
\hline MÉDIA & 0,89 & 1,21 & & $9,04^{\mathrm{A}}$ & $8,90^{A}$ & \\
\hline
\end{tabular}

${ }^{1}$ Valores seguidos de mesma letra minúscula na mesma coluna não apresentam diferença significativa pelo Teste $\mathrm{SNK}(\mathrm{P}<0,05)$.

${ }^{2}$ Médias seguidas por mesma letra maiúscula na mesma linha não apresentam diferença significativa pelo Teste $\mathrm{SNK}$ (P>0,05)

Tabela 2. Comprimento $(\mathrm{cm})$ e local de inserção do músculo cremáster em caprinos com diferentes configurações escrotais: grupo I, escroto único; grupo II, bipartição escrotal até $50 \%$ do comprimento testicular; e grupo III, bipartição escrotal superior a 50\% do comprimento testicular

\begin{tabular}{|c|c|c|c|c|c|c|}
\hline \multirow[b]{2}{*}{ GRUPO } & \multicolumn{3}{|c|}{ COMPRIMENTO $(\mathrm{cm})$} & \multicolumn{3}{|c|}{ LOCAL DE INSERÇÃO (\%) } \\
\hline & Direito & Esquerdo & Média $^{2}$ & $\begin{array}{c}\text { Funículo } \\
\text { Espermático }\end{array}$ & $\begin{array}{l}\text { Até cabeça do } \\
\text { epidídimo }\end{array}$ & $\begin{array}{l}\text { Até o } \\
\text { testículo }\end{array}$ \\
\hline I & 19,66 & 19,08 & $19,37^{\mathrm{a}}$ & 20,00 & 80,00 & 0,00 \\
\hline II & 18,56 & 18,66 & $18,61^{\mathrm{a}}$ & 50,00 & 30,00 & 20,00 \\
\hline III & 20,28 & 19,84 & $20,06^{\mathrm{a}}$ & 30,00 & 50,00 & 20,00 \\
\hline MÉDIA $^{1}$ & $19,50^{\mathrm{A}}$ & $19,19^{\mathrm{A}}$ & & 33,33 & 53,33 & \\
\hline
\end{tabular}

${ }^{\mathrm{T}}$ Médias seguidas por mesma letra maiúscula na mesma linha não apresentam diferença significativa pelo Teste SNK (P>0,05). ${ }^{2}$ Médias seguidas por mesma letras minúsculas na mesma coluna não apresentam diferença significativa pelo Teste $\mathrm{SNK}(\mathrm{P}<0,05)$

Mediante análise estatística das médias (Tabela 3), percebeu-se que o comprimento do segmento da artéria testicular contido no funículo espermático apresentou média superior $(\mathrm{P}<0,05)$ no grupo III $(152,80 \mathrm{~cm})$, seguido pelo grupo II
$(121,59 \mathrm{~cm})$ e grupo I $(103,25 \mathrm{~cm})$. Nos grupos I e II, as médias apresentadas para o comprimento da artéria foram inferiores aos valores descritos em pequenos ruminantes (CARVALHAL et al., 2000), enquanto que no grupo III esse valor foi superior. 
Tabela 3. Comprimento $(\mathrm{cm})$ da artéria testicular contida no funículo espermático em caprinos com diferentes configurações escrotais: grupo I, animais com escroto único; grupo II, bipartição escrotal até 50\% do comprimento testicular; e grupo III, bipartição superior a 50\% do comprimento testicular

\begin{tabular}{lccc}
\hline GRUPO & \multicolumn{3}{c}{ COMPRIMENTO DA ARTÉRIA TESTICULAR } \\
\cline { 2 - 4 } & DIREITO & ESQUERDO & MÉDIA $^{1}$ \\
\hline I & 103,71 & 102,79 & $103,25^{\mathrm{c}}$ \\
II & 119,45 & 123,73 & $121,59^{\mathrm{b}}$ \\
III & 155,04 & 150,56 & $152,80^{\mathrm{a}}$ \\
\hline
\end{tabular}

${ }^{\mathrm{T}}$ Médias seguidas por mesma letras minúsculas na mesma coluna não apresentam diferença significativa pelo Teste $\mathrm{SNK}(\mathrm{P}<0,05)$

Os estudos sobre o segmento da artéria testicular, presente no funículo espermático, revelaram que, em $95 \%$ da amostra total estudada, a artéria apresentava-se única (Figura 3 - A) e em 5\%, ramificada. No entanto, essas ramificações mostraram-se divergentes entre os grupos avaliados. Dessa forma, em um caprino do grupo II, o antímero direito bifurcou-se a $23,5 \mathrm{~cm}$ de seu início no funículo e os ramos apresentaram-se com 87,0 e 91,0 $\mathrm{cm}$ de comprimento (Figura 3 - B), enquanto que, em outro caprino do mesmo grupo, a bifurcação ocorreu a $113,8 \mathrm{~cm}$ do início de seu trajeto e os ramos apresentaram-se com $24,5 \mathrm{~cm}$ de comprimento, sofrendo anastomose ao final do trajeto (Figura 3 C). No grupo III, a artéria testicular a $109,9 \mathrm{~cm}$ de seu comprimento no funículo, emitiu um ramo com lúmen de diâmetro reduzido e $7,5 \mathrm{~cm}$ de extensão, sofrendo anastomose ao final de seu trajeto (Figura 3 - D). Em bovinos, a artéria testicular apresenta-se bifurcada em $45 \%$ dos indivíduos, ramificando-se lateral e medialmente à linha média do funículo espermático (POLGUJ et al., 2011). Segundo NORONHA et al. (2001), essas eventuais divisões da artéria testicular, ao percorrer o funículo espermático, representam apenas variações anatômicas desses vasos sem, no entanto, caracterizarem fator de significância para as trocas térmicas. ALMEIDA et al. (2008b) concluíram que a origem, distribuição e localização das artérias testiculares são similares nos ruminantes domésticos e não apresentam variações relacionadas ao grau de divisão escrotal em caprinos.

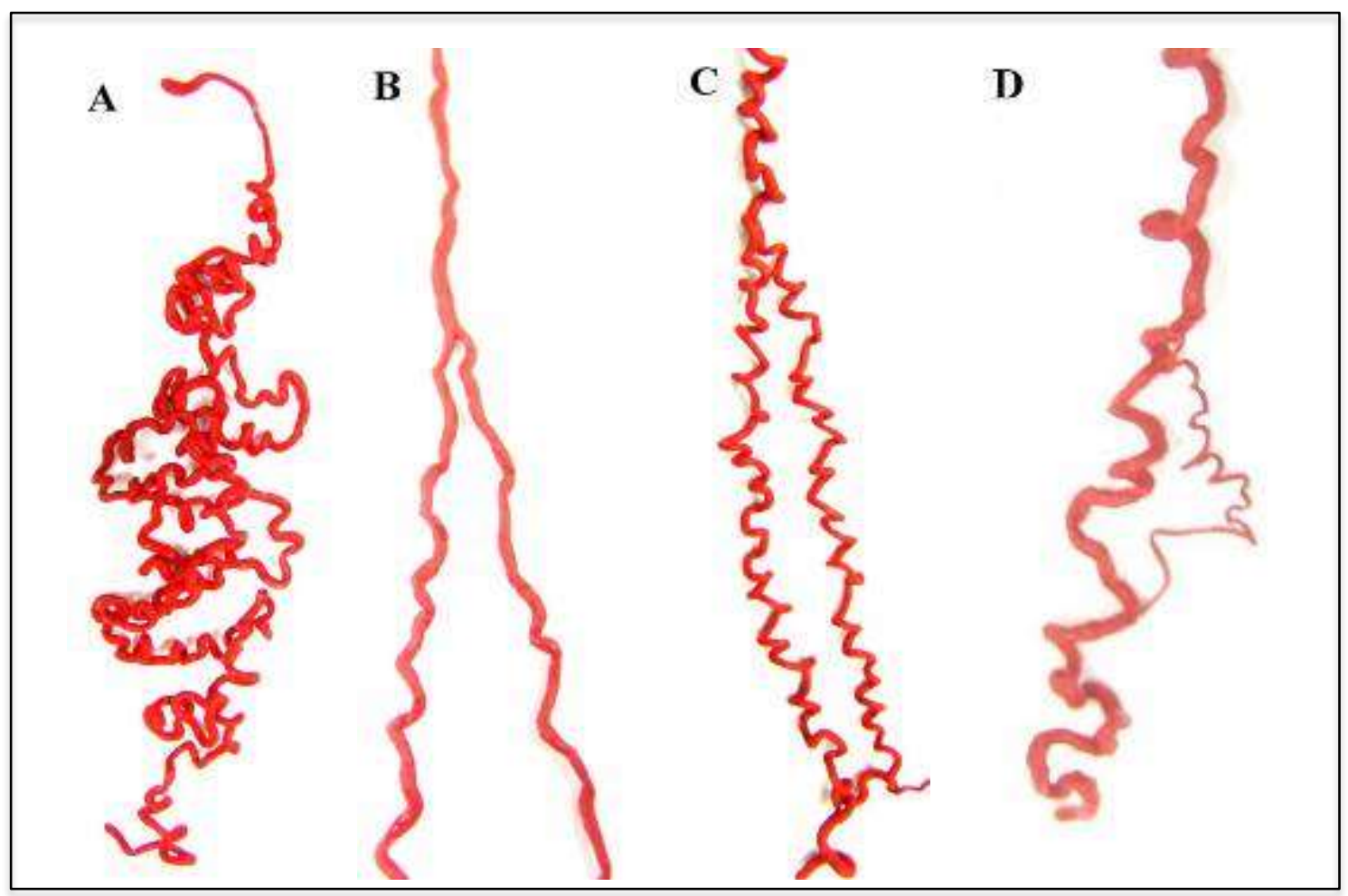

FIGURA 3. Fotografia dos modelos em látex da artéria testicular de caprino adulto, mostrando as variações anatômicas do segmento funicular da artéria: segmento único enovelado (A); segmento com divisão (B); segmento com bifurcação e posterior anastomose $(\mathrm{C})$; segmento com um ramo de fino calibre que anastomosa-se posteriormente (D) 
De acordo com MACHADO JÚNIOR et al. (2009), caprinos com escroto bipartido possuem termorregulação testicular facilitada devido à maior área de pele do escroto em contato com o ambiente. NUNES et al. (2010) afirmam, ainda, que a termorregulação em caprinos com escroto bipartido é efetiva pela grande quantidade de glândulas sudoríparas encontradas na epiderme do escroto desses animais.

Este estudo permitiu concluir que os caprinos com escroto bipartido, superior a $50 \%$ do comprimento testicular, apresentam maior diâmetro e comprimento do funículo espermático e maior extensão do segmento da artéria testicular contido no funículo espermático. Essas características podem facilitar as trocas térmicas entre sangue arterial e venoso, por proporcionarem uma maior área de contato entre eles. A disposição do tecido adiposo, em posição subcapsular, circundando e isolando o conjunto vásculo-nervoso do funículo das estruturas adjacentes, ducto deferente e artérias epididimárias, poderia favorecer, na região distal do funículo espermático, a manutenção de uma temperatura inferior à do corpo. Nos caprinos com escroto não bipartido, os vasos, em região subcapsular, encontram-se rodeados por tecido adiposo, o que poderia dificultar as trocas de calor entre os vasos desses animais.

\section{REFERÊNCIAS}

ALMEIDA, M.M.; ASSIS NETO, A.C.; PENNO, A.K.; CONDE JÚNIOR, A.M.; MENEZES, D.J.A.; PEREIRA, G.R.; AZEVÊDO, L.M.; CARVALHO, M.A.M. Testicular arteries systematization based on different levels of scrotal configuration in caprines. Ciência Rural, v.38, n.5, p.1308 - 1312, 2008a.

ALMEIDA, M.M.; CARVALHO, M.AM.; MACHADO JÚNIOR, A.A.N.; RIGHI, D.A.; XAVIER, F.G.; CONDE JÚNIOR, A.M.; BOMBONATO, P.P. Efeito do grau de bipartição escrotal sobre a vascularização arterial do escroto de caprinos nativos do Estado do Piauí. Brazilian Journal of Veterinary Research and Animal Science, v.45, n.3, p.167 - 173, 2008 b.

BRITO, L.F.C.; SILVA, A.E.D.F.; BARBOSA, R.T.; KASTELIC, J.P. Testicular thermoregulation in Bos indicus, crossbred and Bos taurus bulls: relationship with scrotal, testicular vascular cone and testicular morphology, and effects on semen quality and sperm production. Theriogenology, v.61, p. 511 - 528, 2004.

CARVALHAL, R.; BORELLI, V.; MIGLINO, M.A. Estudo morfológico do funículo espermático em ovinos da raça Corriedale (Ovis aries, L. 1758). Brazilian Journal of Veterinary Research and Animal Science, v.37, n.5, p. p.348-354, 2000.
CEZAR, K.L.R.; GUERRA, M.M.P.; SANTOS, R.M.B.; CÂMARA, D.R.; PINHEIRO JUNIOR, J.W.; SILVA, R.D.; OLIVEIRA, R.R.; MELO, P.R.M.; SILVA, S.V.; WISCHRAL, A. Influência da configuração escrotal sobre a eficiência reprodutiva de caprinos nativos criados no sertão de Pernambuco. Revista Brasileira de Reprodução Animal, Supl., n.5, p.115 - 117, 2002.

MACHADO JÚNIOR, A.A.N.; MIGLINO, M.A.; MENEZES, D.J.A.; ASSIS NETO, A.C.; LEISER, R.; SILVA, R.A.B.; CARVALHO, M.A.M. Influence of the bipartite scrotum on the testicular andscrotal temperatures in goats. PesquisaVeterinária Brasileira, v.29, n.10, p.797 - 802, 2009.

NORONHA, P. B.; PEDUTTI NETO, J.; BORELLI, V. Aspectos morfológicos do funículo espermático de jumentos (Equus asinus - Linnaeus, 1758) da raça Pega. Brazilian Journal of Veterinary Research and Animal Science. v.38, n.5, p. 209-213, 2001. Disponível em http://www.scielo.br/scielo.php?script=sci_arttext\&pid=S 1413-95962001000500002\&lng=en\&nrm=iso Acesso em 15 mai. 2011.

NUNES, A.S.; CAVALCATE FILHO, M.F.; MACHADO JÚNIOR, A.A.N.; ABREU-SILVA, A.N.; CONDE JÚNIOR, A.M.; SOUZA, J.A.T.; CARVALHO, M.A.M. Descrição histológica do escroto de caprinos nativos do Estado do Piauí, segundo o grau de bipartição escrotal. Ciência Rural, v.40, n.8, p.1808 - 1813, 2010.

NUNES, J.F.; RIERA, G.S.; SILVA, A.E.F.D.; PONCE DE LEON, F.A.; LIMA, F.A.M. Características espermáticas de caprinos moxotó de acordo com a morfologia escrotal. Sobral: EMBRAPA/CNPCaprinos,1983. 11p.(Circular técnica, 6). Disponível http://www.infoteca.cnptia.embrapa.br/handle/doc/514303 . Acesso em 20 abr. 2011.

PASCUALY, O.S.; ELOY, A.X. Evaluacion de parametros reproductivos en machos ovinos y caprinos en el CNPC. Sobral: IICA/EMBRAPA/CNPC, 1985. 22p. (Boletim técnico).

POLGUJ, M.; JEDRZEJEWSKI, K.S.; TOPOL, M. Angioarchitecture of the bovine spermatic cord. Journal of Morphology, v.272, p. 497 - 502, 2011.

SANTOS, D.O.; SIMPLÍCIO, A.A.; MACHADO, R. Características escroto-testiculares e do ejaculado em bodes mestiços submetidos à insulação escrotal. Arquivo Brasileiro de Medicina Veterinária e Zootecnia, v.50, n.3, p.287-297, 1998.

SETCHELL, B.P.; BREED, W.G. Anatomy, Vasculature, and innervation of the male reproductive tract. In: KNOBIL and NEILL'S. Physiology of Reproduction, 3 ed., Austrália: Elsevier, 2006. p. 771 - 825.

VIANA, W.G.; BORELLI, V. Contribuição ao estudo do funículo espermático em bovinos da raça Nelore. Brazilian Journal of Veterinary Research and Animal Science, v.28, n.1, p.11 - 17, 1991. 